\title{
Micro-grinding temperature prediction considering the effects of crystallographic orientation
}

\author{
Man Zhao ${ }^{1,2}$, Xia Ji ${ }^{1, *}$, and Steven Y. Liang ${ }^{1,2}$ \\ ${ }^{1}$ College of Mechanical Engineering, Donghua University, Shanghai 201620, PR China \\ ${ }^{2}$ George W. Woodruff School of Mechanical Engineering, Georgia Institute of Technology, Atlanta, GA 30332, USA
}

Received: 8 February 2019 / Accepted: 8 April 2019

\begin{abstract}
Tensile stress and thermal damage resulting from thermal loading will reduce the anti-fraying and anti-fatigue of workpieces, which is undesirable for micro-grinding, so it is imperative to control the rise of temperature. This investigation aims to propose a physical-based model to predict the temperature with the process parameters, wheel properties and material microstructure taken into account. In the calculation of heat generated in the micro-grinding zone, the triangular heat-flux distribution is adopted. The reported energy partition model is also utilized to calculate the heat converted into the workpiece. In addition, the Taylor factor model is used to estimate the effects of crystallographic orientation ( $\mathrm{CO}$ ) and its orientation distribution function $(\mathrm{ODF})$ on the workpiece temperature by affecting the flow stress and grinding forces in micro-grinding. Finally, the physical model is verified by performing micro-grinding experiments using the orthogonal method. The result proves that the prediction matches well with the experimental values. Besides, the single-factorial experiments are conducted with the result showing that the model with the consideration of the variation of Taylor factor improves the accuracy of the temperature prediction.
\end{abstract}

Keywords: Temperature / flow stress / crystallographic orientation / micro-grinding / Taylor factor

\section{Introduction}

Aluminum alloy AA7075 $(\mathrm{Al}-\mathrm{Zn}-\mathrm{Mg}-\mathrm{Cu})$ is an ideal material for the aerospace industries because of the high strength and light-weight [1] and its utilization in aircraft is extensive [2]. The micron form accuracy of aerospace products requires an ultra-precision machining method to achieve. Micro-grinding is the typical final procedure in the machining of micro-features with the micrometer finish, while high heat is generated in the process owning to the high specific energy. Thermally induced stress primarily leads to the tensile residual stress [3] and thermal damage $[4,5]$ which will deteriorate the mechanical properties of the workpiece. Therefore, it is crucial for engineers to analytically model the thermal effect and control the workpiece temperature.

The calculation of the workpiece temperature consists of modeling the heat flux distribution and the energy partition. The moving heating source theory is widely used to analyze the thermal effects [6], then the temperature rise concerning both time and space are calculated. The heat flux distribution is modeled to be different shapes

\footnotetext{
* e-mail: jixia@dhu.edu.cn
}

according to the various machining process, such as triangular, rectangular, and parabolic. The quadratic curve heat flux distribution model was proposed for external cylindrical grinding with the improved accuracy of the predictive temperature [7]. The triangular heat flux distribution was more consistent with the measured data of temperature than other distribution for plane grinding based on the inverse heat transfer analysis [8]. Pang et al. [9] proposed a shape parameter which determined the heat flux distribution and the value was fitted against experimental data. The investigation indicated that the shape of heat source influenced the grinding temperature significantly. Wang et al. [10] reported that the heat source profile varies with the variation of Peclet numbers and contact angles, which are related to the grinding conditions.

Energy partition refers to the ratio of the heat conducted into the workpiece to the total grinding energy. Some techniques have been proposed to calculate the energy partition, including calorimetric method and inverse heat transfer method. Rowe et al. [11-13] proposed calorimetric method to obtain the heat partition entering workpiece and theoretically model the temperature. Gou and Milkin [14,15] developed three inverse heat transfer methods, including temperature matching, integral, and 
Table 1. Thermal properties of materials.

\begin{tabular}{llllllll}
\hline Material & $\begin{array}{l}\text { Modulus' } \\
\text { elasticity } \\
(E)(\mathrm{MPa})\end{array}$ & $\begin{array}{l}\text { Passion's } \\
\text { ratio }(v)\end{array}$ & $\begin{array}{l}\text { Density } \\
(\rho)\left(\mathrm{kg} / \mathrm{m}^{3}\right)\end{array}$ & $\begin{array}{l}\text { Thermal } \\
\text { diffusivity } \\
(\alpha)\left({ }^{\circ} \mathrm{C}^{-1}\right)\end{array}$ & $\begin{array}{l}\text { Specific } \\
\text { heats }\left(C_{p}\right) \\
\left(\mathrm{J} / \mathrm{kg}{ }^{\circ} \mathrm{C}\right)\end{array}$ & $\begin{array}{l}\text { Thermal } \\
\text { conductivity } \\
(K)\left(\mathrm{W} / \mathrm{m}{ }^{\circ} \mathrm{C}\right)\end{array}$ & References \\
\hline 7075 -T6 & $7.2 \mathrm{E} 4$ & 0.33 & 2810 & $6.6 \mathrm{E}-5$ & 860 & 173 & {$[23]$} \\
CBN & $7.2 \mathrm{E} 5$ & 0.13 & 3400 & $1.12 \mathrm{E}-4$ & 682 & 1300 & 0.5 \\
Polyimide film & - & - & 2900 & $2.06 \mathrm{E}-7$ & 837 & {$[24]$} & {$[25]$} \\
Constantan & - & - & - & $8.3 \mathrm{E}-6$ & 396 & 22 & \\
\hline
\end{tabular}

sequential methods, to evaluate the energy partition by measuring the temperature of subsurface in grinding. In a large number of researches, the heat partition to the workpiece was taken as a constant along the grinding zone. Kohil et al. [16] reported an experimental investigation about the heat partition in grinding with different wheels. The results indicated that high thermal conductivity of the abrasive wheel leads to low grinding energy transported to the workpiece as heat. For the measurement of the workpiece temperature, the thermocouple method and the infrared method were widely used [17-19]. The above literature has clearly made the heat flux distribution and heat partition ratio in calculating micro-grinding temperature and proposed the methods to measure the workpiece temperature. Meanwhile, to calculate grinding power which is transferred into heat energy, it is essential to model the mechanical load firstly with the consideration of the wheel properties, the process parameters, and the crystallographic effects of workpiece material.

The micro-machining process is significantly influenced by the material microstructure with the microscale tool cutting through grain boundaries. The material crystallographic orientations (COs) and the orientation distribution functions (ODFs) play a key role in the mechanical properties of material anisotropy. In micro-grinding, Park and Liang [4] coupled the mechanical and thermal stress in modeling the flow stress with considering the material microstructure. The developed thermal model took the chip formation and plowing components as the heat sources and considered the heat generated in micro-grinding zone as a triangular heat source. The heat partition ratio was analytically calculated using the model proposed by Hahn [20], and calibrated experimentally based on the embedded thermocouple measurement. However, the analytical model did not consider the variation of COs in the calculation of grinding temperature. For polycrystalline materials, the effect of texture on the material strength named Taylor factor and it was assumed to be a constant of 3.06 [21]. Zhao et al. [22] proposed a physical model of Taylor factor for polycrystalline materials which quantified the effect of material COs and the ODF on the flow stress in micro-grinding. However, to the best of knowledge from this paper's authors, few quantitative models of the temperature were developed by considering the effects of texture in micro-grinding polycrystalline materials.

In this investigation, the temperature distribution in the workpiece is calculated based on the micro-grinding temperature model derived from the micro-grinding force and flow stress models which take the effect of COs and the ODF into account. Meanwhile, the proposed temperature model also considers process parameters as well as the micro-grinding wheel properties. Furthermore, the temperature model was experimentally calibrated by comparing the prediction of maximum temperature with the experimental data. Finally, the sensitivity analysis of temperature to process parameters and Taylor factor were conducted and proposed suggestions for engineers to control the workpiece temperature.

\section{Experimental material}

Alloy aluminum 7075-T6 (AA7075-T6) is an FCC metal, and there is no phase transformation in the micro-grinding process. The thermal properties of materials are presented in Table 1.

In this study, 20 samples of AA7075-T6 were taken from the same plate with the same dimension. In addition, the plate has rolling direction (RD), transverse direction (TD), and the normal direction (ND) [26], the initial texture are various on the three different surfaces but same on the same surface. The initial sample with the dimension of $42 \times 11 \times 10 \mathrm{~mm}^{3}$ includes three parts. Two parts of which are in the same dimension of $12 \times 11 \times 10 \mathrm{~mm}^{3}$, the other one is $18 \times 11 \times 10 \mathrm{~mm}^{3}$, and the three parts are connected by screw. The 20 initial samples were divided into two groups, each group has ten specimens. The dimensions of samples in group A were milled to be $42 \times 10.6 \times 9.6 \mathrm{~mm}^{3}$ with the depth of cut $0.2 \mathrm{~mm}$ on each milled surface. The others in group B were milled to be $42 \times 10.4 \times 9.4 \mathrm{~mm}^{3}$ with the depth of cut $0.3 \mathrm{~mm}$ on each milled surface. The microstructure of samples evolved after milling and various textures were obtained owning to different depth of cut. Therefore, four kinds of AA7075-T6 specimens with different textures were obtained and numbered the ND surfaces with the dimension of $42 \times 10.6 \mathrm{~mm}^{2}$ in group A as NO.1, the TD surfaces with the dimension of $42 \times 9.6 \mathrm{~mm}^{2}$ as NO.2, the ND surfaces with the dimension of $42 \times 10.4 \mathrm{~mm}^{2}$ in group B as NO.3, the TD surfaces with the dimension of $42 \times 9.4 \mathrm{~mm}^{2}$ as NO.4. The initial samples and the milled samples for both groups $\mathrm{A}$ and $\mathrm{B}$ are shown in Figure 1.

This research utilizes Electron Back Scatter Diffraction (EBSD) to measure the microstructure of material with the COs as well as the ODFs obtained by analysis software. The texture micrographs of the four samples are shown in Figure 2. 
In the paper, CO is represented by Miller indices [27], which are used to indicate directions and planes of crystals. Miller indices form a notation system in crystal: $[u v w]$ and $\langle u v w\rangle$ specify a direction and a family of directions, respectively, $(h k l)$ and $\{h k l\}$ represent a plane and a family of planes, respectively. The measured data of the texture of samples are listed in Table 2.

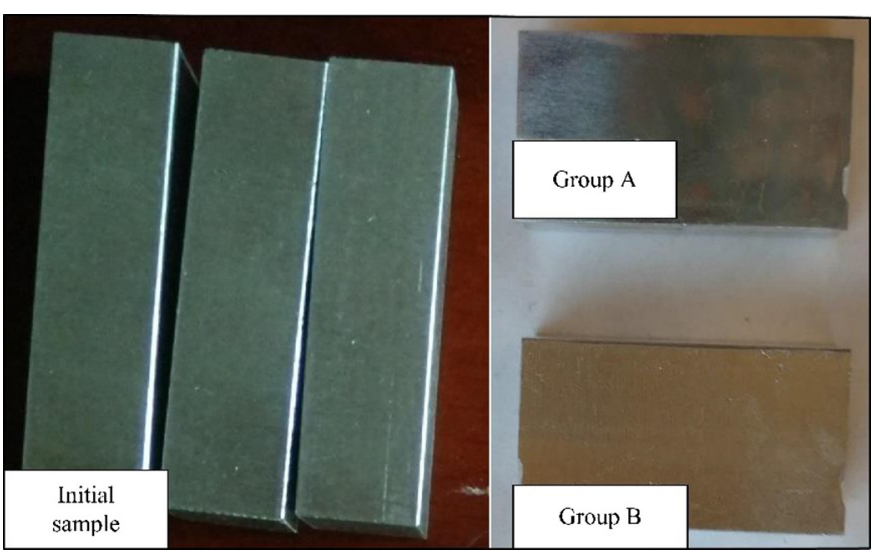

Fig. 1. The initial samples and the milled samples both for groups $\mathrm{A}$ and $\mathrm{B}$.

\section{Calculation method}

\subsection{Taylor factor model for polycrystalline materials}

To model the micro-grinding temperature by considering the effect of the COs and ODFs, the Taylor factor model is proposed, as expressed by equation (1).

$$
M=\sum_{j=1}^{m} f_{j} * M_{j}^{F}
$$

where $M^{F}$ is the Taylor factor model of single FCC crystal proposed by Zhao [22], where $f_{j}$ represents the ODF of crystalline with the orientation of $j$.

The flow stress model with considering the Taylor factor model is shown as follows:

$$
\begin{aligned}
\sigma_{0}= & \left(A+B \varepsilon^{n}\right)\left(1+C \ln \frac{\dot{\varepsilon}}{\dot{\varepsilon}_{0}}\right)\left(1-\left(\frac{T_{0}-T_{w}}{T_{m}-T_{w}}\right)^{m}\right) \\
& +M \alpha_{1} G b_{1} \sqrt{\rho_{1}}+K_{\mathrm{HP}} / \sqrt{D_{d}}
\end{aligned}
$$

where $\alpha_{1}$ is a geometrical constant of material which is obtained by fitting the experimental stress-strain curve and represents the contribution from dislocation to shear stress, $M$ refers to the Taylor factor of polycrystalline material, $b_{1}$ is the Burgers vector, $\rho_{1}$ denotes the dislocation

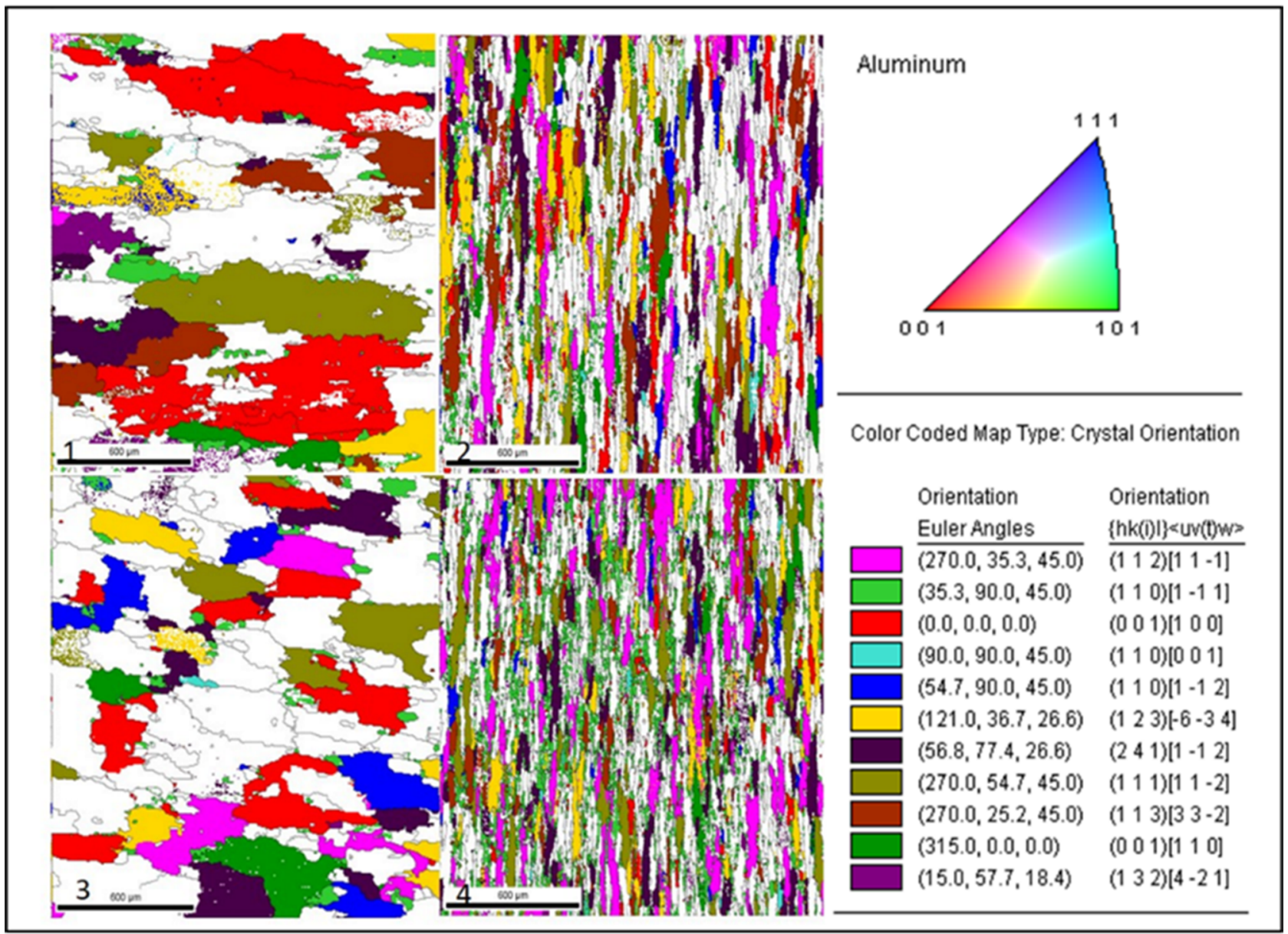

Fig. 2. The texture of the four AA7075 specimens. 
Table 2. The CO and the corresponding ODFs of samples.

\begin{tabular}{lllll}
\hline $\begin{array}{l}\text { Crystal orientation } \\
\{h k l\}\langle\text { Pvw }\end{array}$ & \multicolumn{4}{c}{ Partition fraction or crystal orientation distribution } \\
\cline { 2 - 5 }$(112)[11 \overline{1}]$ & NO.1 & NO.2 & NO.3 & NO.4 \\
$(110)[1 \overline{1} 1]$ & 0.0240 & 0.0537 & 0.0130 & 0.0517 \\
$(001)[100]$ & 0.0230 & 0.0913 & 0.0413 & 0.0670 \\
$(110)[001]$ & 0.0773 & 0.0350 & 0.1120 & 0.0203 \\
$(110)[1 \overline{1} 2]$ & 0.0343 & 0.0153 & 0.0010 & 0.0210 \\
$(123)[\overline{6} \overline{3} 4]$ & 0.0277 & 0.0590 & 0.0243 & 0.1073 \\
$(241)[1 \overline{1} 2]$ & 0.0337 & 0.0743 & 0.0250 & 0.1060 \\
$(111)[11 \overline{2}]$ & 0.0393 & 0.0560 & 0.1287 & 0.0723 \\
$(113)[33 \overline{2}]$ & 0.0210 & 0.0480 & 0.0670 & 0.0327 \\
$(001)[110]$ & 0.0340 & 0.0427 & 0.0523 & 0.0233 \\
$(132)[4 \overline{2} 1]$ & 0.0140 & 0.0147 & 0.0200 & 0.0057 \\
\hline
\end{tabular}

density, and $G$ is the elasticity modulus. The value of $K_{\mathrm{HP}}$ is computed by $K_{\mathrm{HP}}=M \sqrt{\frac{\tau_{4} 4 G b_{1}}{(1-v) \pi}}, \tau_{b}=0.057 G$, and $v$ is the Poisson's ratio.

Shear flow stress is calculated as follows:

$$
\tau_{s}=\frac{\sigma}{\sqrt{3}}
$$

The resultant force of individual grit in tangential and normal directions is expressed as:

$$
\left\{\begin{aligned}
F_{t g, \text { chip }}= & \int_{\alpha_{\mathrm{cr}}}^{\alpha} \frac{\tau_{s} \cos \left(\beta_{k}-\alpha_{k}\right)}{\sin \varphi_{k} \cos \left(\varphi_{k}+\beta_{k}-\alpha_{k}\right)} 2 r^{2} \cos ^{2} \alpha_{k} d \alpha_{k} \\
& +\frac{\tau_{s} \cos (\beta-\alpha)(t-r(1+\sin \alpha)) r}{\sin \varphi \cos (\varphi+\beta-\alpha)} \\
F_{n g, \text { chip }}= & \int_{\alpha_{\mathrm{cr}}}^{\alpha} \frac{\tau_{s} \sin \left(\beta_{k}-\alpha_{k}\right)}{\sin \varphi_{k} \cos \left(\varphi_{k}+\beta_{k}-\alpha_{k}\right)} 2 r^{2} \cos ^{2} \alpha_{k} d \alpha_{k} \\
& +\frac{\tau_{s} \cos (\beta-\alpha)(t-r(1+\sin \alpha)) r}{\sin \varphi \cos (\varphi+\beta-\alpha)}
\end{aligned}\right.
$$

where $\varphi$ is the shear angle, $\beta$ is the friction angle, $\alpha$ is the nominal rake angle, and $\varphi_{k}$ is obtained using slip line model [28]. $\alpha_{\mathrm{cr}}$ is the critical rake angle, which is given by $\alpha_{\mathrm{cr}}=\sin ^{-1} \frac{\left(t_{\mathrm{cr}}-r\right)}{r}$.
The single grit forces are presented as

$$
F_{t g}=F_{t g, \text { chip }}+F_{t g, \text { plowing }}+F_{t g, \text { rubbing }}
$$

where $F_{t g \text {,plowing }}, F_{t g, \text { rubbing }}$ are plowing and rubbing force of individual grit.

Then, the total grinding forces are calculated as

$$
F_{t}=C_{d} w l_{c} F_{t g}
$$

where $C_{d}$ is the of dynamic cutting edge density, $w$ is the grinding width, and $l_{c}$ is the contact length.

\subsection{Modeling the micro-grinding temperature}

In the micro-grinding process, the grains contact the unfinished surface one by one with the rotation of the grinding wheel and experience sliding, plowing, and chip formation from the beginning to the end of the interference zone. The two-dimensional (2D) heat transfer is assumed with a 2D heat flux on the contact surface, which is attributed to the depth of cut and is far less than width of grinding, the surface speed is much more than the feedrate, and the heat loss. The grinding energy resulting from the three components almost totally converts into heat owing to the high specific energy of micro-grinding.

The grinding temperature filed was usually analyzed by the moving heat source theory with the workpiece modeled as a semi-infinite solid [6]. The shape of the heat source 


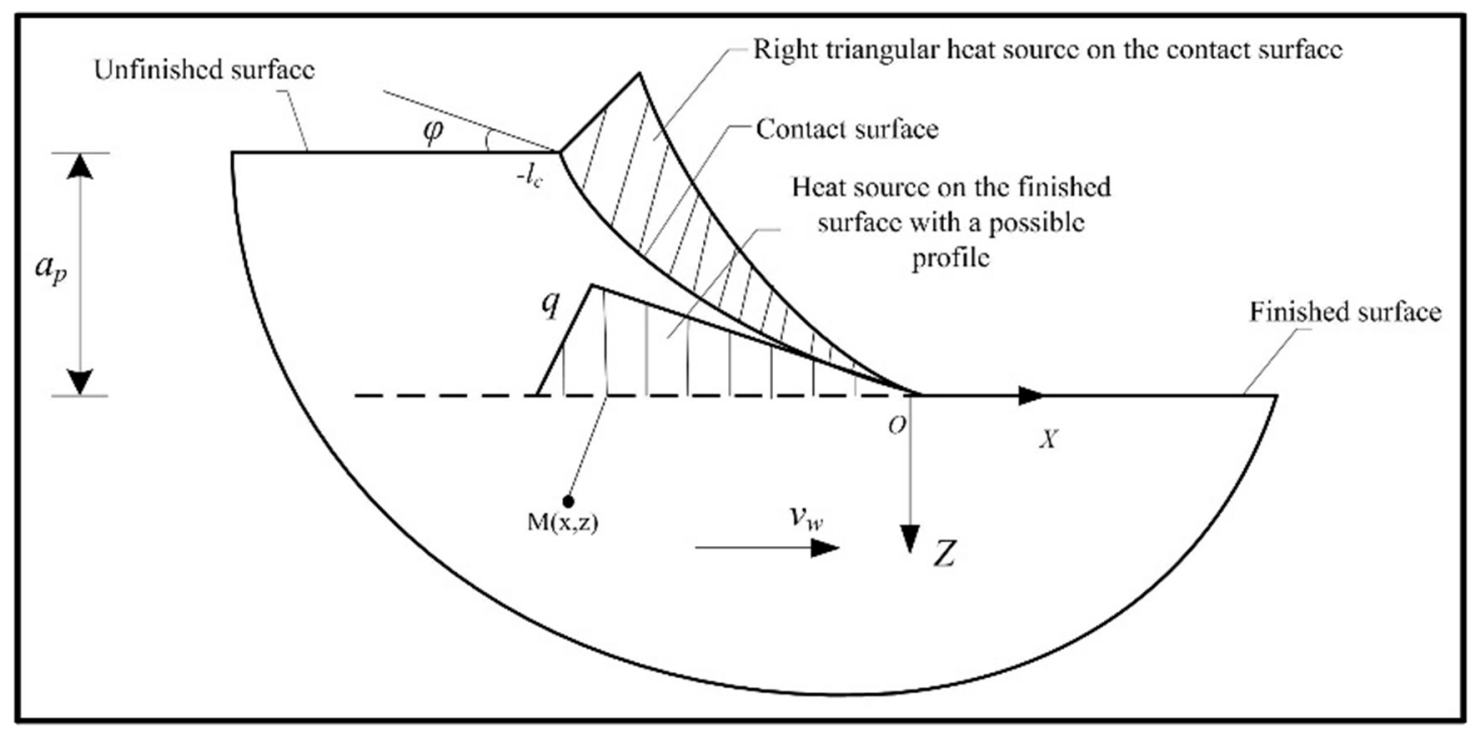

Fig. 3. Heat flux distribution on the finished and contact surface.

profile is dependent on the contact angle and the Peclet number. The contact angle $\varphi$ is calculated by $\sin \varphi=a_{p} / l_{c}$, and the Peclet number $\mathrm{Pe}$ is calculated by $\mathrm{Pe}=V_{w} \cdot l_{c}$ / $(4 \cdot \alpha)$, where $\alpha$ is the thermal diffusivity of the workpiece material. Wang et al. [28] concluded that the shape is modeled as right angular when the contact angle is less than $5^{\circ}$; the shape is triangular when the contact angles range from $5^{\circ}$ to $10^{\circ}$ and the Peclet number is less than 5 ; and the shape is parabolic when the contact angle is larger than $10^{\circ}$ and the Peclet number is larger than 5 . In the investigation, all of the contact angles under the grinding conditions are less than $5^{\circ}$. Therefore, the shape of the heat source profile is assumed as right triangular. It is shown the heat flux shape on the contact surface and the finished surface in Figure 3 with the coordinate axis built in the beginning of the interference zone.

The heat source profile on the finished surface is assumed as right triangular and the shape function is expressed by equation (7).

$$
f\left(\zeta_{i}\right)=\frac{-2 \cdot \zeta_{i}}{l_{c}} \quad-l_{c} \leq \zeta_{i} \leq 0
$$

The total grinding heat $q_{t}$ generated in the process can be expressed by equation (8), which is related to the tangential force, surface speed, feedrate, contact length, and cutting width. The models of cutting, plowing, and rubbing forces have been reported by Zhao et al. [29], and the tangential force has been calculated with the consideration of the effects of material COs and the ODFs.

$$
q_{t}=F_{t}\left(V+V_{w}\right) /\left(l_{c} \cdot w\right) .
$$

The specific power to chips $e_{\mathrm{ch}}$ is assumed to be close to the limiting chip energy, and $e_{\mathrm{ch}}$ is approximately $6 \mathrm{~J} / \mathrm{mm}^{3}$ for aluminum alloy material [30]. The heat flux to chips $q_{\mathrm{ch}}$ can be expressed by equation (9), which is also related to the depth of cut, feedrate, and contact length.

$$
q_{\mathrm{ch}}=e_{\mathrm{ch}} a_{p} V_{w} / l_{c} .
$$

The heat partition ratio to the workpiece is described as a solid-body heat specification boundary condition model, as appropriate to homogeneous material thermal condition [20], which is expressed by equation (10).

$$
R_{w}=\left(1+\frac{0.97 k_{g}}{\sqrt{r V\left(k \rho c_{p}\right)_{w}}}\right)^{-1}
$$

where $k_{q}$ is the thermal conductivity of the grit, $k_{w}$ is the thermal conductivity of the workpiece, $\rho_{w}$ is the workpiece density, and $c_{p w}$ is the workpiece specific heat. This investigation focuses on dry micro-grinding without coolant, therefore the heat mainly transfers into chips, wheel, and workpiece. The mean heat flux to the workpiece is calculated by equation (11)

$$
q_{w}=\left(q_{t}-q_{\mathrm{ch}}\right) \cdot R_{w} .
$$

Finally, the moving heat source elements are calculated by integrating over the contact length. The temperature response of the point $M$ in the workpiece can be described by equation (12) [6]:

$$
\begin{array}{r}
T_{(X, Z)=} \frac{q_{w}}{\pi k_{w}} \int_{-l c}^{0} f\left(\zeta_{i}\right) \cdot \exp \left(\frac{-V_{w}\left(X-l_{i}\right)}{2 \alpha_{w}}\right) \\
\cdot K_{0}\left\{\frac{V_{w}\left[\left(X-l_{i}\right)^{2}+Z^{2}\right]^{1 / 2}}{2 \alpha_{w}}\right\} d \zeta_{i}
\end{array}
$$




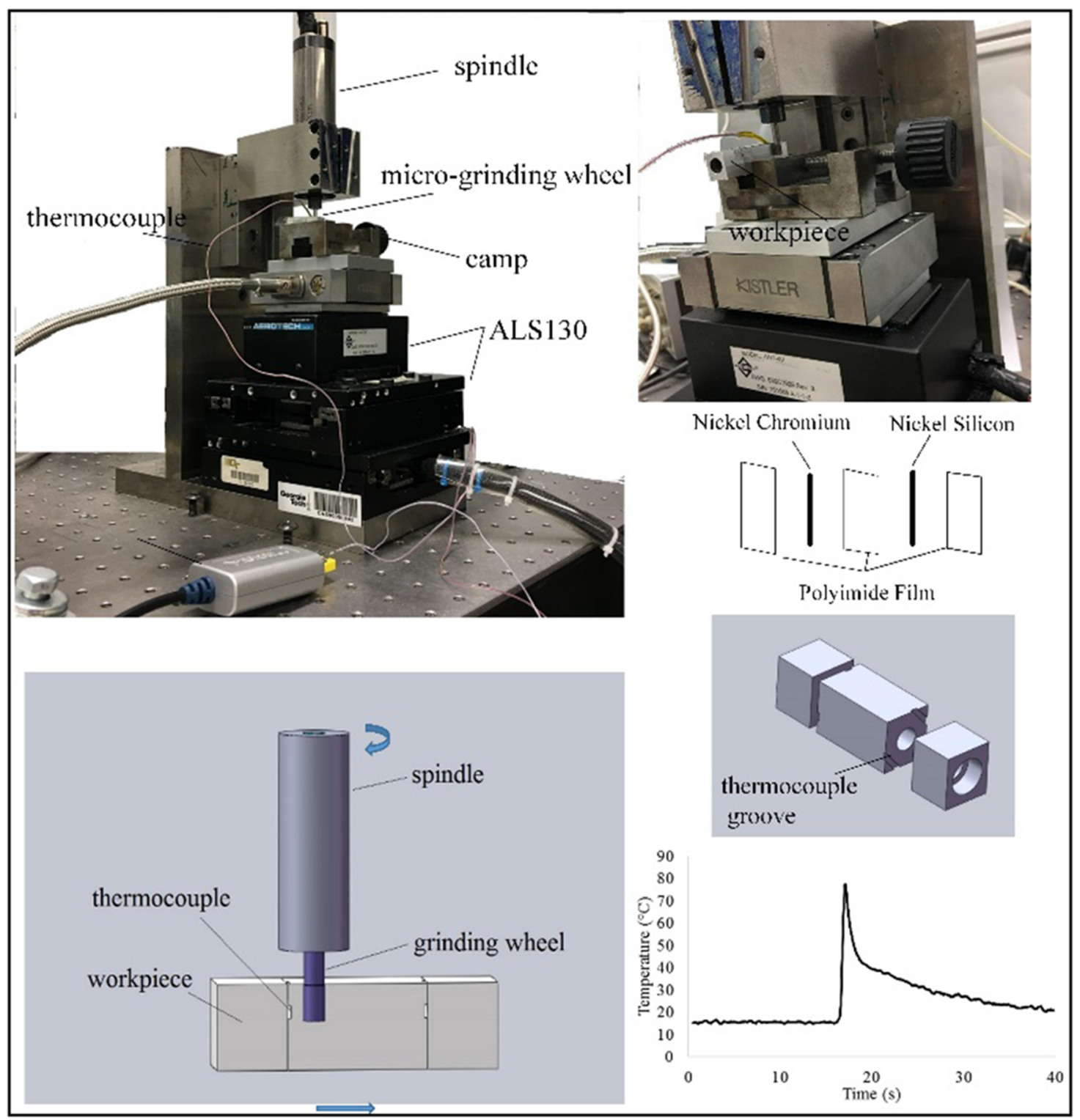

Fig. 4. Schematic diagram of micro-grinding and temperature measurement method.

where $K_{0}$ is the second kind modified Bessel function and $\alpha_{w}$ is the thermal diffusivity of the workpiece.

\section{Experimental method}

Micro-grinding experiments are performed on a miniaturized machine tool, which is shown in Figure 4. This miniaturized machine tool consists of five main subparts, including a spindle, cutting tool, positioning stage, frame, and inspection device with the dimensions of $320 \times 260 \times 130 \mathrm{~mm}^{3}$. The maximum rotational speed of the wheel spindle is $60000 \mathrm{rpm}$ and the diameter of the CBN grinding wheel is $3 \mathrm{~mm}$. The thermocouple method is utilized to measure the microgrinding temperature in this investigation. A contacting single-pole thermocouple of nickel chromium and nickel silicon as well as the USB-TC01 is used to measure the surface temperatures in the micro-grinding zone. Before the microgrinding process, the copper and constantan end are insulated by polyimide film with the thickness of $0.0125 \mathrm{~mm}$. Then the two ends are welded into one node owing to the plastic deformation during micro-grinding, and the signals are acquired by a temperature data acquisition system, which is based on the Labview system platform and an acquisition program written by NI-DAQ Assistant. Figure 4 shows the schematic diagram of micro-grinding, the temperature measurement method, and one of the temperature test result.

A series of micro-grinding experiments using orthogonal method are carried out to validate the predictive model. The inputs of the model include surface speed, depth of cut, feedrate, and Taylor factor, and each factor has four levels. The $L_{16}$ orthogonal arrays are listed in Table 3.

To analyze the effect of COs and the ODFs on microgrinding temperature, the single-factorial experiments are carried out with the single variable of Taylor factor, with the grinding parameters listed in Table 4. 
Table 3. $L_{16}$ orthogonal arrays of micro-grinding experiments.

\begin{tabular}{lllll}
\hline $\begin{array}{l}\text { Case } \\
\text { number }\end{array}$ & $\begin{array}{l}\text { Surface } \\
\text { speed }(\mathrm{m} / \mathrm{s})\end{array}$ & $\begin{array}{l}\text { Feedrate } \\
(\mathrm{mm} / \mathrm{min})\end{array}$ & $\begin{array}{l}\text { Depth of } \\
\text { cut }(\mu \mathrm{m})\end{array}$ & $\begin{array}{l}\text { Taylor } \\
\text { factor }\end{array}$ \\
\hline 1 & 1.57 & 1 & 1 & 5.60 \\
2 & 1.57 & 5 & 10 & 8.44 \\
3 & 1.57 & 10 & 20 & 9.11 \\
4 & 1.57 & 20 & 30 & 9.75 \\
5 & 3.14 & 1 & 10 & 8.44 \\
6 & 3.14 & 5 & 1 & 9.75 \\
7 & 3.14 & 10 & 30 & 9.11 \\
8 & 3.14 & 20 & 20 & 5.60 \\
9 & 6.28 & 1 & 20 & 9.75 \\
10 & 6.28 & 5 & 30 & 8.44 \\
11 & 6.28 & 10 & 1 & 9.11 \\
12 & 6.28 & 20 & 10 & 5.60 \\
13 & 9.42 & 1 & 30 & 9.11 \\
14 & 9.42 & 5 & 20 & 5.60 \\
15 & 9.42 & 10 & 10 & 9.75 \\
16 & 9.42 & 20 & 1 & 8.44 \\
\hline
\end{tabular}

Table 4. Process parameters of the fundamental experiment.

\begin{tabular}{lllll}
\hline & $\begin{array}{l}\text { Surface } \\
\text { speed }(\mathrm{m} / \mathrm{s})\end{array}$ & $\begin{array}{l}\text { Feed rate } \\
(\mathrm{mm} / \mathrm{min})\end{array}$ & $\begin{array}{l}\text { The depth of } \\
\text { cutting }(\mu \mathrm{m})\end{array}$ & $\begin{array}{l}\text { Taylor } \\
\text { factor }\end{array}$ \\
\hline 17 & & & & 5.60 \\
18 & & & 10 & 9.75 \\
19 & 6.28 & 10 & & 9.11 \\
20 & & & & 8.44 \\
\hline
\end{tabular}

\section{Model validation and discussion}

\subsection{Validation of the temperature model}

The distribution of grinding temperature in the workpiece is computed by equation (12). Take case 4 for example, the temperature distribution is plotted in Figure 5a. The temperature model is validated by comparing the prediction of maximum temperature with the experimental data, the maximum temperature is obtained from the temperature profile and experimental data are collected with the variation of the depth of cut, feed rate, the surface speed, and the Taylor factor of workpiece. The comparisons between the measured data and the prediction of temperature are shown in Figure 5b.

The comparison in Figure 5b shows a good agreement between the predictive and measured temperature within the experimental range, which indicates that the proposed model of temperature is accurate. Meanwhile, it suggests that considering the effect of $\mathrm{CO}$ in modeling microgrinding temperature is reasonable.

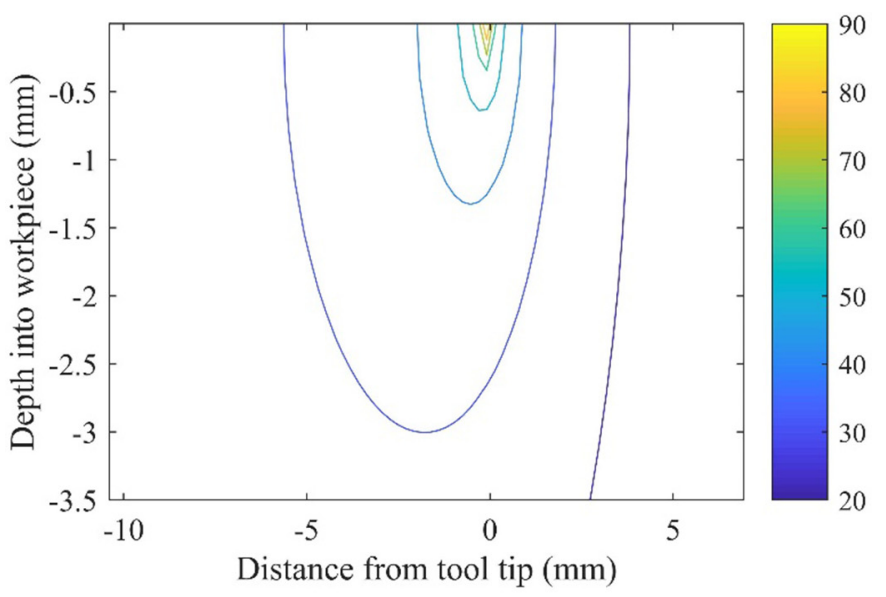

(a)

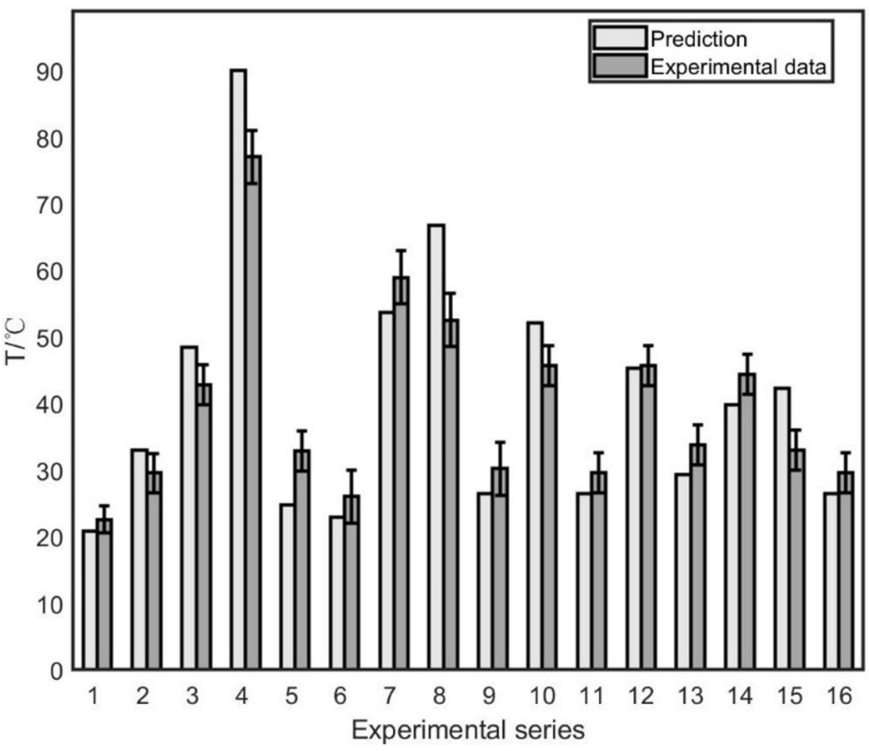

(b)

Fig. 5. (a) Temperature distribution in workpiece, and (b) comparison between experimental data and the predictions of grinding temperature.

To describe the effect of undeformed chip thickness on micro-grinding temperature clearly, Figure 6 a shows the comparison between the critical depth of cut and the undeformed chip thickness of each case, and the contributions of forces on temperature are shown in Figure 6b.

The result shows that the contributions of chip formation, plowing, and rubbing forces on temperature vary with the undeformed chip thickness. It is concluded that the undeformed chip thickness plays a key role in understanding the mechanism of the micro-grinding process. When the undeformed chip thickness is less than the critical depth of cut, the plowing and rubbing force are the main contributions to the micro-grinding temperature with the plowing force is dominant, which is related to the hardness of material. All of the grinding energy induced by plowing and sliding forces are converted to heat; when the 


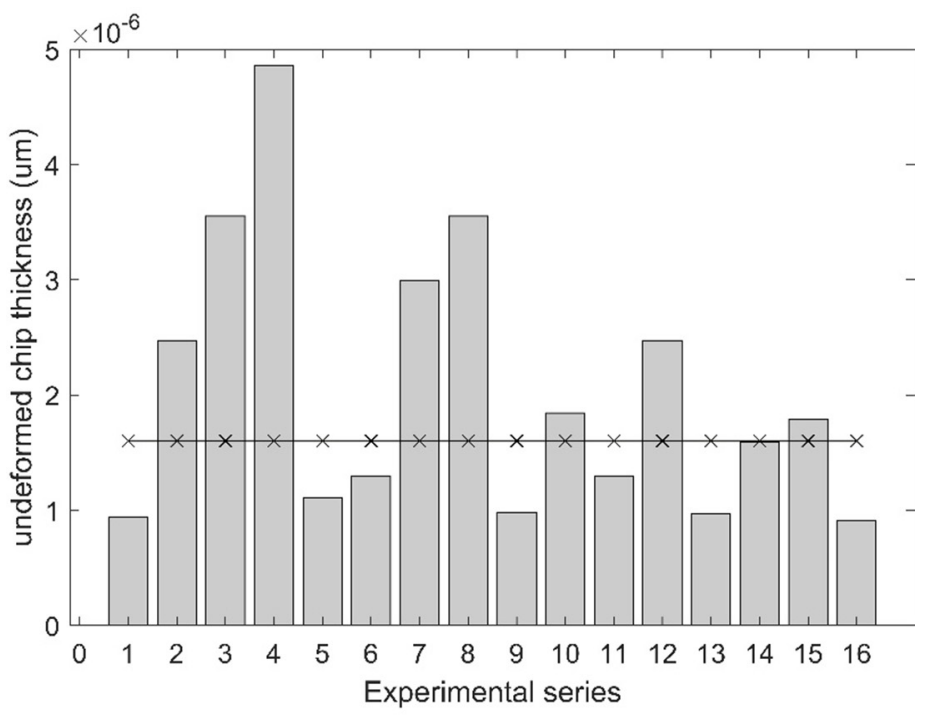

(a)

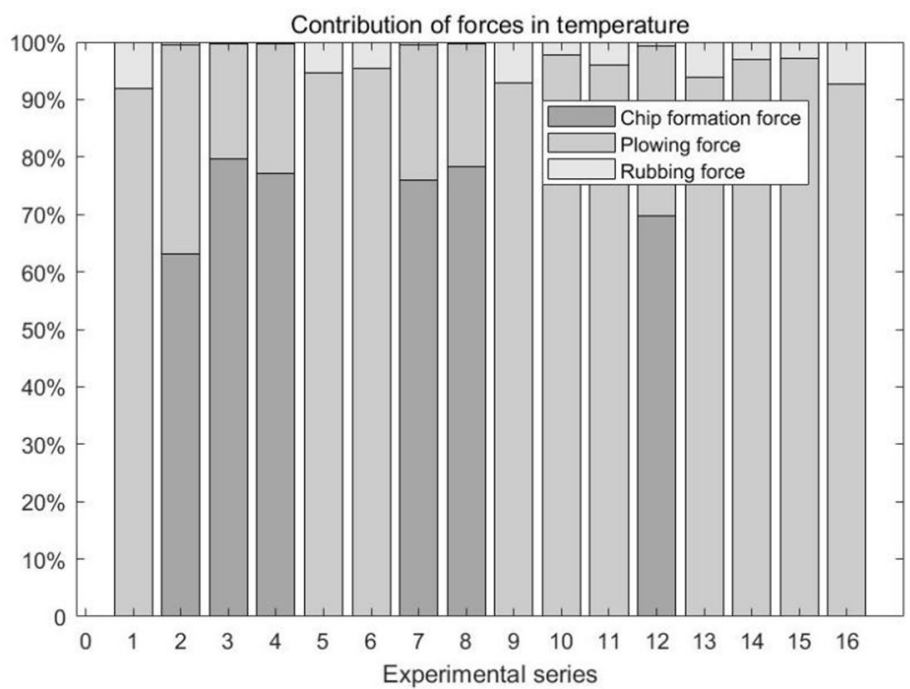

(b)

Fig. 6. (a) The comparison between the undeformed chip thickness and the critical depth of cut, (b) contribution of the chip formation and the plowing force on temperature.

undeformed chip thickness is thicker than the critical depth of cut, the contribution of the chip formation force is up to $80 \%$ on the temperature, which is related to the flow stress influenced by the COs and the ODFs. A part of the grinding energy generated by chip formation force is transferred to chip formation. In the mechanism, the large plasticity occurs when the chips generate and the slip systems are activated, which are determined by the COs of the workpiece material and the cutting direction.

\subsection{Effect of COs on the temperature}

To analyze the effect of COs on the micro-grinding temperature, the single-factorial experiments were conducted with the single variable of Taylor factor. The proposed temperature model considering the variation of Taylor factor is compared with the other two models as well as experimental values, which is shown in Figure 7.
Model 1 considers the Taylor factor as the fixed value of 3.06 , model 2 does not take the effect of grain size into account. The predictions resulting from the three different models are compared with the experimental data, as shown in Figure 7 . The temperatures predicted by model 1 is not able to capture the magnitude of the experimental data with the maximum error exceeds $25 \%$. The predictions resulted from model 2 agrees well with the measured data with the maximum error less than $8 \%$. Model 3 proposed in the investigation agrees well with the trend and magnitude of experimental data with errors about $5 \%$. The results show that the model considering the variation of Taylor factor improves the accuracy of micro-grinding temperature. The comparisons also indicate that COs of material have a more significant influence on the micro-grinding temperature compared with grain size. The increase in the Taylor factor causes the increasing plastic deformation, which leads higher grinding energy conducted to heat. 


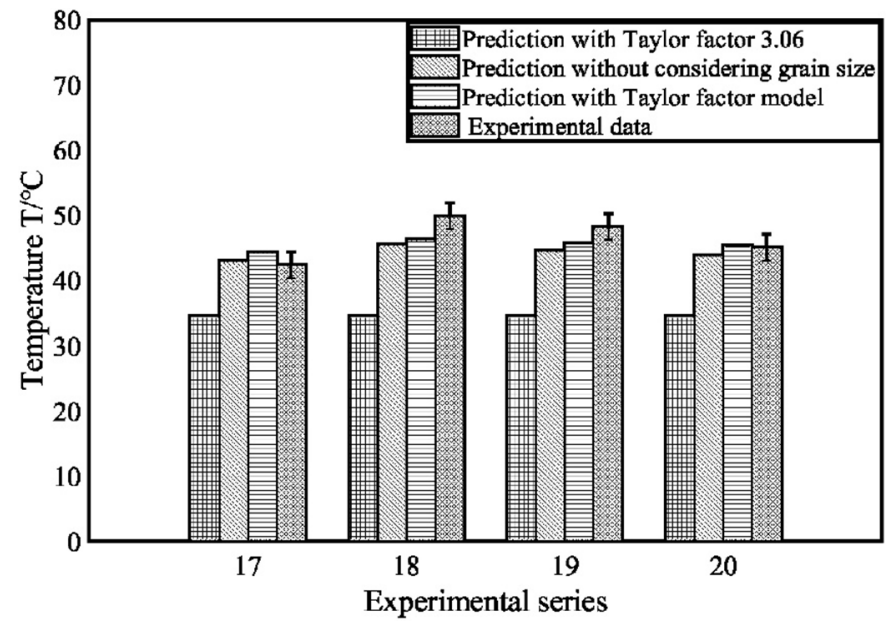

Fig. 7. Comparison between experimental data and predictions of temperature.

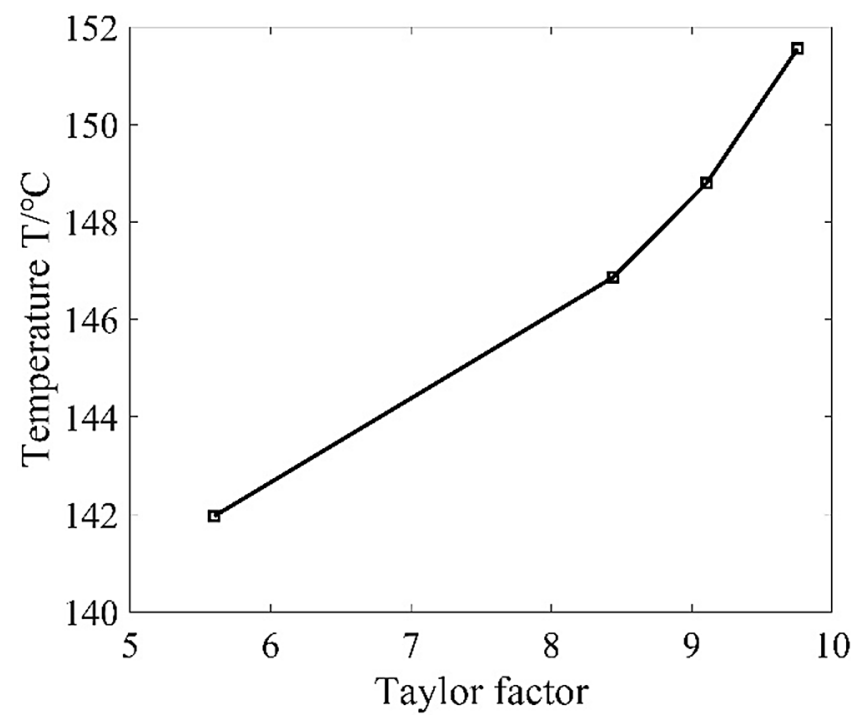

Fig. 8. The effect of Taylor factor on grinding temperature.

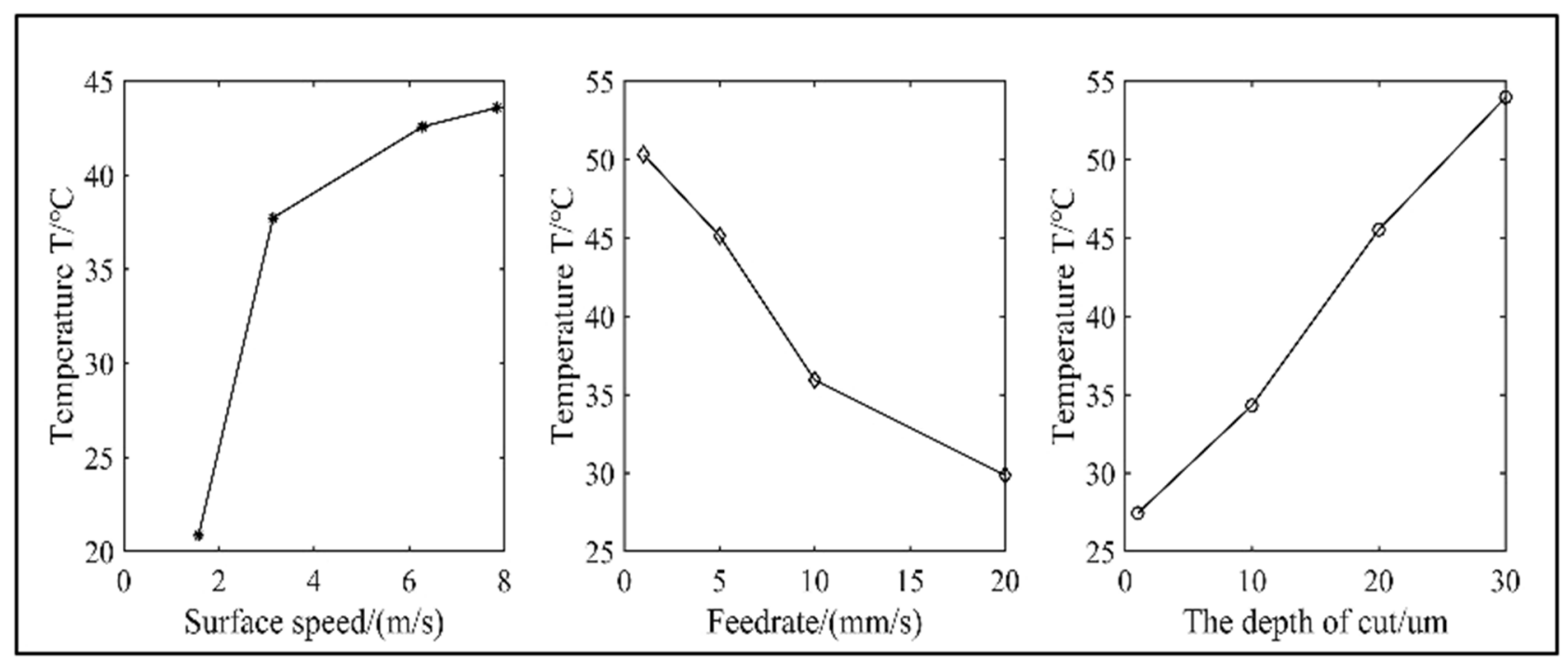

Fig. 9. Sensitivity analysis of the grinding temperature to the main effects.

Figure 8 shows the effect of Taylor factor on the grinding temperature.

The results demonstrate that Taylor factor reveals positive effects on the grinding temperature, which illustrates that improving the Taylor factor is unfavorable to micro-grinding. In mechanism, the increase in the Taylor factor causes the increasing plastic deformation, which leads higher grinding energy conducted to heat.

\subsection{Sensitivity analysis of temperature to process parameters}

A sensitivity analysis of grinding temperature to input parameters including the surface speed, the feed rate, and the depth of cut is studied, with the exact ranges of the input parameters listed in Table 3 . The sensitivity of the temperature to the tree input parameters is shown in Figure 9.

The results demonstrate that the feedrate has a negative correlation with the temperature, while the surface speed and the depth of cut reveal positive effects on the temperature. The result illustrates that improving the surface speed and the depth of cut is unfavorable and improving the feed rate is favorable to micro-grinding.

In mechanism, with the increase in the surface speed and the depth of cut more grits will participate in the interaction between tool and workpiece, which induces more heat in the interference zone. While larger is the feedrate, faster moves the heat resource on the workpiece surface, shorter time works on the workpiece and more heat transfer into the air, eventually lower is the grinding temperature. 


\section{Conclusions}

The temperature distribution in workpiece was calculated by representing the heat source with Bessel functions and integrating over the contact length between the wheel and the workpiece. In the calculation of grinding power, the mechanical load was modeled by considering the process parameters, the workpiece material microstructure, and the micro-grinding wheel topography. This paper predicted the effect of texture on micro-grinding temperature on the basis of the developed Taylor factor model which quantifies the effects of the COs and the ODFs on the flow stress. In computations, the material $\mathrm{CO}$ and its ODF were obtained by the EBSD test.

The micro-grinding experiments using orthogonal method with four-level were performed to verify the proposed model. The predictions of the maximum temperature matched well with the measured data which indicated that the model is reasonable to predict the temperature. Meanwhile, single-factorial experiments were conducted to analyze the effect of Taylor factor on the temperature. The predictions were compared with experimental data and the result showed that the temperature model considering the variation of Taylor factor improved the accuracy of prediction with the maximum deviation less than $5 \%$ within the tested range of parameters. Owing to the Taylor factor is related to the $\mathrm{CO}$ of workpiece and cutting direction, the temperature will be controlled though governing the angle between $\mathrm{CO}$ and cutting direction in the micro-grinding process.

By comparing the undeformed chip thickness with the critical depth of cut, the chip forms when the undeformed chip thickness is thicker than the critical depth of cut, and the chip formation force becomes the main contributors to temperature, whereas the plowing and rubbing forces are the contributors to the temperature when the undeformed chip thickness is less than the critical depth of cut. The temperature of the later condition is larger than that of the former condition, while the material removal rate is lower than that of the former condition. So, it is important to control the undeformed chip thickness by controlling the process parameters. In addition, the sensitivity analysis of process parameters is studied with a wide range. The results demonstrate that with increase of the feedrate as well as decrease of the surface speed and depth of cut the Taylor factor is favorable both for decreasing the temperature rise in workpiece and for improving the material removal rate.

\section{Nomenclature}

$\begin{array}{ll}\text { Symbol } & \text { Instruction } \\ A, B, C, m, n & \text { Johnson-Cook parameters } \\ a_{p} & \text { The depth of cut } \\ b_{1} & \text { Burger vector } \\ \mathrm{C}_{\mathrm{Pw}} & \text { Specific heat of workpiece } \\ D & \text { Grit diameter } \\ E & \text { Workpiece elasticity modulus } \\ e_{\mathrm{ch}} & \text { Chip energy } \\ F_{t} & \text { Tangential force }\end{array}$

$\begin{array}{ll}M_{1} & \text { Taylor factor of polycrystalline material } \\ k_{w} & \text { Thermal conductivity of workpiece } \\ l_{c} & \text { The total contact length } \\ T & \text { The maximum temperature } \\ \alpha_{1} & \text { Material constant } \\ \alpha_{w} & \text { Thermal diffusivity } \\ \rho_{1} & \text { Density of dislocation } \\ \rho_{w} & \text { Material density } \\ A_{s}, k_{s} & \text { Parameters of wheel topography } \\ C_{s} & \text { Static cutting edge density } \\ C_{d} & \text { Dynamic cutting edge density } \\ q_{t} & \text { Total grinding heat flux } \\ q_{\mathrm{ch}} & \text { Heat flux to chip } \\ q_{w} & \text { Heat flux to workpiece } \\ R_{w} & \text { Energy partition } \\ t & \text { Undeformed chip thickness } \\ T_{(X, Z)} & \text { The temperature of point (X,Z) } \\ v & \text { Poisson's ratio } \\ V & \text { Wheel speed } \\ V_{w} & \text { Workpiece speed or feed rate } \\ w & \text { Cutting width } \\ \dot{\varepsilon} & \text { Plastic strain rate } \\ \dot{\varepsilon}_{0} & \text { material constant } \\ \varepsilon & \text { plastic strain }\end{array}$

\section{References}

1. G. Quan, Y. Mao, G. Li, W. Lv, Y. Wang, J. Zhou, A characterization for the dynamic recrystallization kinetics of as-extruded 7075 aluminum alloy based on true stress-strain curves, Comput. Mater. Sci. 55 (2012) 65-72

2. G.E. Totten, D.S. MacKenzie, Handbook of aluminum: physical metallurgy and processes, CRC Press, Boca Raton, 2003

3. Z. Ding, B. Li, S.Y. Liang, Material phase transformation at high heating rate during grinding, Mach. Sci. Technol. 20 (2016) 290-311

4. H.W. Park, S.Y. Liang, Force modeling of microscale grinding process incorporating thermal effects, Int. J. Adv. Manuf. Technol. 44 (2008) 476-486

5. J.B. Chen, Q.H. Fang, J.K. Du, C. Xie, Effect of point heat source on growth of subsurface crack induced in brittle material machining, J Therm. Stresses 40 (2017) 72-85

6. J.C. Jaeger, Moving sources of heat and temperature at sliding contacts, J. Proc. R. Soc. N.S.W. 76 (1942) 203

7. D. Zhu, B. Li, H. Ding, An improved grinding temperature model considering grain geometry and distribution, Int. J. Adv. Manuf. Technol. 67 (2013) 1393-1406

8. N.K. Kim, C. Guo, S. Malkon, Heat flux distribution and energy partition in creep-feed grinding, CIRP Ann. Manuf. Technol. 46 (1997) 227-232

9. J. Pang, C. Wu, Y. Shen, S. Liu, Q. Wang, B. Li, Heat flux distribution and temperature prediction model for dry and wet cylindrical plunge grinding, Proc. Inst. Mech. Eng. Part B: J. Eng. Manuf. (2018). DOI: 10.1177/0954405418815365

10. D. Wang, S. Sun, J. Jiang, X. Liu, The profile analysis and selection guide for the heat source on the finished surface in grinding, J. Manuf. Process. 30 (2017) 178-186

11. W.B. Rowe, S.C.E. Black, B. Mills, H.S. Qi, Analysis of grinding temperatures by energy partitioning, Proc. Inst. Mech. Eng. Part B: J. Eng. Manuf. 210 (1996) 579-588 
12. W.B. Rowe, S.C.E. Black, B. Mills, H.S. Qi, M.N. Morgan, Experimental investigation of heat transfer in grinding, CIRP Ann. Manuf. Technol. 44 (1995) 329-332

13. W.B. Rowe, M.N. Morgan, H.S. Qi, H.W. Zheng, The effect of deformation on the contact area in grinding, CIRP Ann. Manuf. Technol. 42 (1993) 409-412

14. C. Guo, S. Malkin, Inverse heat transfer analysis of grinding, part 2: applications, J. Eng. Ind. 118 (1996) 143-149

15. C. Guo, S. Malkin, Inverse heat transfer analysis of grinding, part 1: methods, J. Eng. Ind. 118 (1996) 137-142

16. S. Kohli, C. Guo, S. Malkin, Energy partition to the workpiece for grinding with aluminum oxide and CBN abrasive wheels, J. Eng. Ind. 117 (1995) 160

17. D. Ross-Pinnock, P.G. Maropoulos, Review of industrial temperature measurement technologies and research priorities for the thermal characterisation of the factories of the future, Proc. Inst. Mech. Eng. Part B: J. Eng. Manuf. 230 (2016) 793-806

18. A.T. Kuzu, K.R. Berenji, B.C. Ekim, M. Bakkal, The thermal modeling of deep-hole drilling process under MQL condition, J. Manuf. Process. 29 (2017) 194-203

19. Y.J. Sun, J. Sun, J.F. Li, Modeling and experimental study of temperature distributions in end milling Ti6Al4V with solid carbide tool, Proc. Inst. Mech. Eng. Part B: J. Eng. Manuf. 231 (2017) 217-227

20. R.S. Hahn, On the nature of the grinding process, in: Proceeding of the 3rd MTDR Conference, 1962, p. 129

21. H. Justinger, G. Hirt, Estimation of grain size and grain orientation influence in microforming processes by Taylor factor considerations, J. Mater. Process. Technol. 209 (2009) $2111-2121$
22. M. Zhao, X. Ji, B. Li, S.Y. Liang, Investigation on the influence of material crystallographic orientation on grinding force in the micro-grinding of single-crystal copper with single grit, Int. J. Adv. Manuf. Technol. 90 (2016) 3347-3355

23. Z.S. Ding, Research on surface integrity and process optimal criterion of micro-grinding, Donghua University, Shanghai, China, 2016

24. A. Lefebvre, P. Vieville, P. Lipinski, C. Lescalier, Numerical analysis of grinding temperature measurement by the foil/ workpiece thermocouple method, Int. J. Mach. Tool. Manuf. 46 (2006) 1716-1726

25. C.f.w. CO., Constantan tc type t std, 2018. http://www. calfinewire.com/datasheets/100859-constantantctypeestd. html.

26. L. Wang, H. Yu, Y.-S. Lee, M.-S. Kim, H.-W. Kim, Effect of microstructure on hot tensile deformation behavior of 7075 alloy sheet fabricated by twin roll casting, Mater. Sci. Eng. A 652 (2016) 221-230

27. W. Tayon, R. Crooks, M. Domack, J. Wagner, A.A. Elmustafa, EBSD study of delamination fracture in Al-Li alloy 2090, Exp. Mech. 50 (2008) 135-143

28. P.L.B. Oxley, The mechanics of machining: an analytical approach to assessing machinability, Halsted Press, New York, UK, 1989

29. M. Zhao, X. Ji, S.Y. Liang, Influence of aa7075 crystallographic orientation on micro-grinding force, Proceedings of the Institution of Mechanical Engineers, Proc. Inst. Mech. Eng. Part B: J. Eng. Manuf. (2018). DOI: 10.1177/ 0954405418803706

30. S. Malkin, N.H. Cook, The wear of grinding wheels: part $2-$ fracture wear, J. Eng. Ind. 93 (1971) 1129

Cite this article as: Man Zhao, Xia Ji, Steven Y. Liang, Micro-grinding temperature prediction considering the effects of crystallographic orientation, Manufacturing Rev. 6, 22 (2019) 